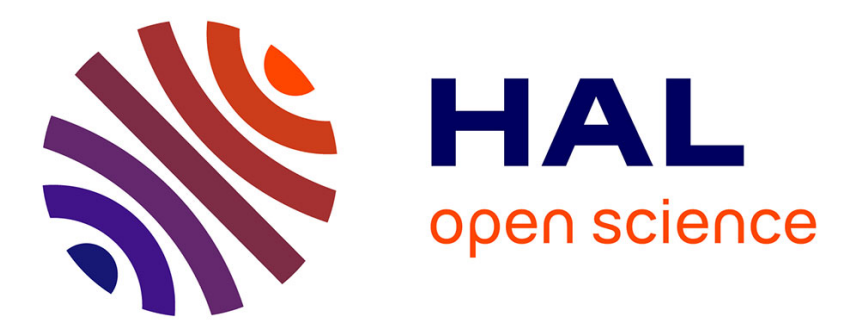

\title{
Language training for various purposes in several languages on a common hypermedia framework
}

Bruce Ingraham, Thierry Chanier, Chris Emery

\section{To cite this version:}

Bruce Ingraham, Thierry Chanier, Chris Emery. Language training for various purposes in several languages on a common hypermedia framework. Computers and Education, 1994, Selected papers from Eurocall 1993, 23 (1-2), pp.107-115. edutice-00672821

\section{HAL Id: edutice-00672821 \\ https://edutice.archives-ouvertes.fr/edutice-00672821}

Submitted on 22 Feb 2012

HAL is a multi-disciplinary open access archive for the deposit and dissemination of scientific research documents, whether they are published or not. The documents may come from teaching and research institutions in France or abroad, or from public or private research centers.
L'archive ouverte pluridisciplinaire HAL, est destinée au dépôt et à la diffusion de documents scientifiques de niveau recherche, publiés ou non, émanant des établissements d'enseignement et de recherche français ou étrangers, des laboratoires publics ou privés. 

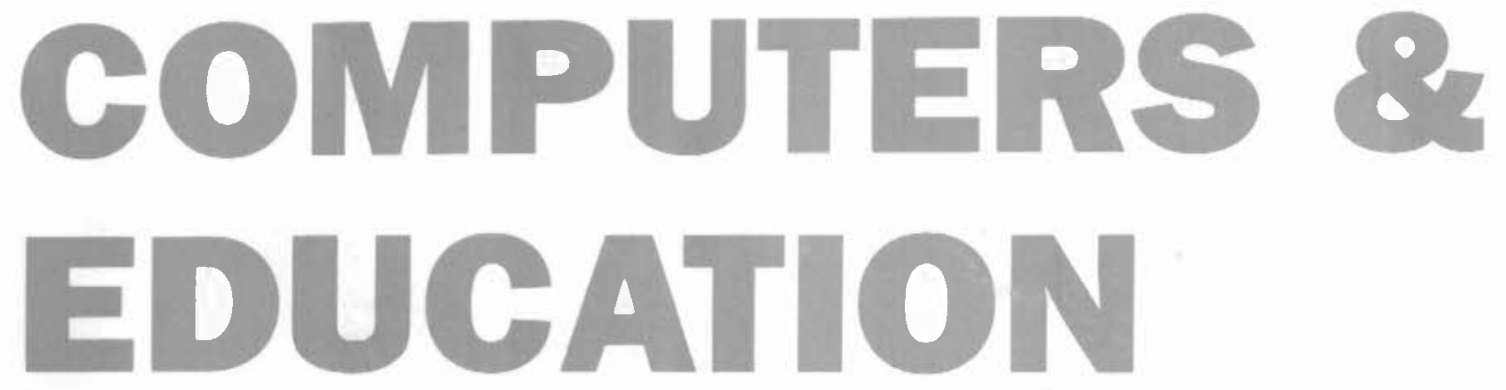

\section{An International Journal}

\section{Editors:}

Michael R. Kibby

Rachelle S. Heller

\section{EMANCIPATION THROUGH LEARNING TECHNOLOGY} Selected Papers from the EUROCALL'93 Conference

Edited by

JUNE THOMPSON

GRAHAM CHESTERS

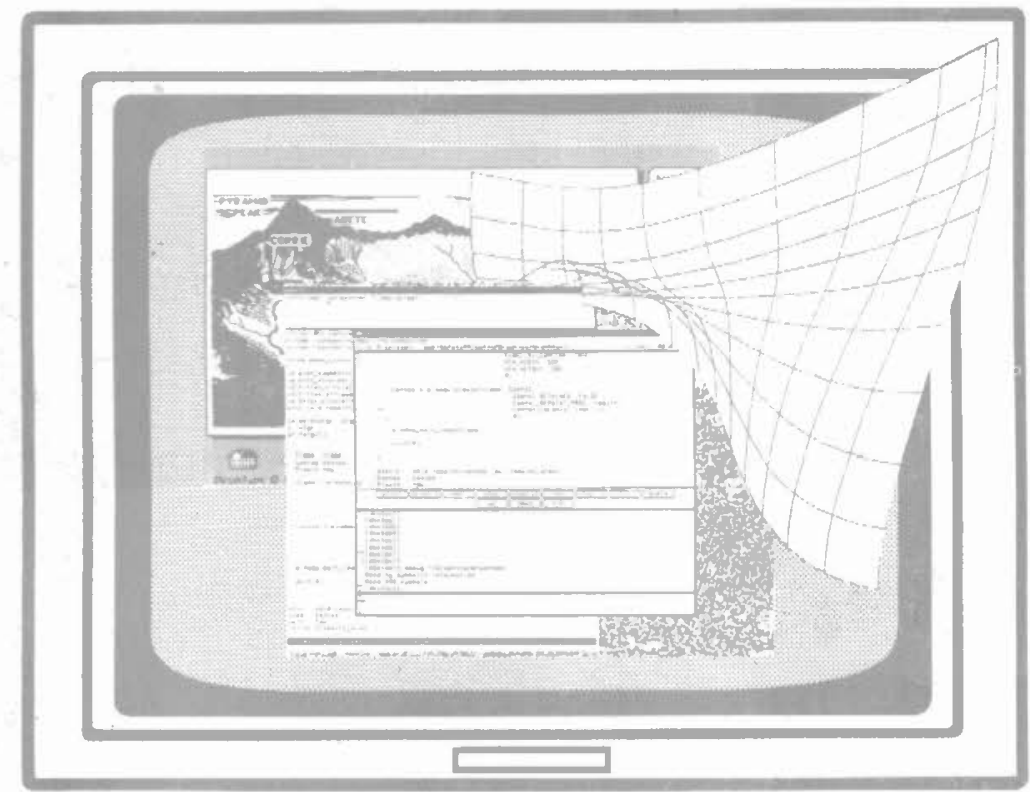




\title{
LANGUAGE TRAINING FOR VARIOUS PURPOSES IN SEVERAL LANGUAGES ON A COMMON HYPERMEDIA FRAMEWORK
}

\author{
Brucr Ingraham,' Thitrry Chanter ${ }^{2}$ and Chris Emery \\ CAMILLE Research Centre, The Language Centre, University of Teesside, Middlesborough. \\ Cleveland TS1 3BA, England [Fax: 0642342067 ; e-mail: camille(a)tees.ac.uk] and 'Département \\ de \\ [Fax: 3373 406443; e-mail: chanier(@)cfdvax.univ-bpclermont.fr]
}

\begin{abstract}
The principal aim of the CAMILLE project is the development and delivery of hypermedia courscware in Dutch, Spanish, French and English. It encompasses the training of general linguistic competencies for beginners (Dutch and Spanish) as well as competencies related to the use of language for specific purposes (French and English). The target audiences include students in science or business. for specific pur o aided multimedia interactive learning cnvironment) is building on the expertise gained at the University ar in detail elscwhere. It consists of ten modules, each composed of lour 1-h units which exploit extensively the interactive voice of both sound and video. Furthermore, hypertext has been used on a software the in learner-controlled navigation through the softwarc. A basic premisc is that France InterActive would provide the CAMILLE project with a state-of-the-art hardware/software platform upon which to construct its courseware.
\end{abstract}

\section{INTRODUCTION}

The use of an cxisting piece of software as a template for multinational and multilingual courseware development has thrown up some interesting questions and problems.

Firstly, using France InterActive as a template for basic Dutch and Spanish courses which have similar linguistic goals raise the issues of:

the portability of hypermedia methodology between languages what, for a given target language, needs to be changed or added to take account of learners' previous linguistic experience in different source languages.

Secondly, using France Interactive as a template for an intermediate course in French for Specific Purposes ("Working in France") which has different or additional linguistic goals has already compelled us to modify the original framework to encompass new kinds of man-machine interactions and new pedagogical requirements.

Finally, the CAMILLE project has shown some of the problems involved in transnational courseware development, e.g. scripting and shooting being done in different countries, and software assembly in others.

Before discussing the nature and potential of the CAMILLE platform, we should define our terms. For present purposes, multimedia should be taken to mean a computing resource capable of displaying textual data, graphical data (still or animated), photographic data (still or moving), and of recording and playing back sound data. These various data types may be displayed simultaneously or sequentially depending on the needs of the resource, but it seems likely that most large-scale systems will provide multiple data windows and that these windows should be capable of displaying differing data types.

How this data is accessed, however, leads to the second important concept, hypertext. Hypertext refers to a system of accessing textual data in which the data is not stored in any particular sequence. The data must, of course, be stored in an orderly manner, but this should not dictate the order in which it is accessed. Ultimately, of course, the data is accessed sequentially, but the 
sequence is determined by the end user rather than by the original author. As such, hypertexts are usually understood to be very open data structures which the user is free to explore at will.

Combining the openness of hypertext with the data richness of multimedia creates hypermedia. That is, a media-rich data environment in which one can move freely from pictures, to video, to sound, to text or any combination of these in a scquence determined by the user.

One of the great advantages of such systems is that they permil users to follow their own train of thought, clarifying issues as they occur to them rather than as they occurred to the authors. More traditional CALL systems tend to be based on a programmed learning approach. They are structured in a tree-like manner in which progress through the lesson is determined by the choices a learner makes at any given moment. Each choicc sends the user down a particular branch of the information available and excludes them from others. They may, of course, retrace their steps along their chosen path and then choose another, but while thcy are on one path they cannot easily access information which is contained on other branches of the knowledge tree. This means that the lesson planners or progammers have to ensure in advance that the learner has already acquired all the information needed to make each new choice. Unfortunately, in a knowledge domain as complex as language, it is almost impossible to plan in advance for all eventualities. In hyper information systems this is unnecessary, because the user can move from any point in the system to any other at will. If, for example, a learner is engaged in an excrcise and needs some grammatical information before making some particular choice, one can, in principle, move directly to that information, then on to a dictionary then to a video clip and then back to the point of choice. However, this freedom of movement, or "navigation", poses its own problems-most commonly the problem of becoming disoriented. As users pursue their train of thought and one question leads to another they may easily lose sight of the original question and become confused or disillusioned. To understand the potential severity of this problem in educational terms, giving somcone unguided free access to a large hypermedia data base would be rather like taking a student to a library and telling them to educate themselves. The persistent might, but the others...?

Countering this problem has been a major issue for educational courseware developers; most of them seem to have devised solutions similar to those dcvcloped in CAMILLE. On the one hand, great care is taken to "signpost" the user's current position and relate it to some specific central location; on the other, data resources are not presented as homogenous, commonly being divided into lesson materials and reference materials.

\section{THE BASIC CAMILLE TEMPLATE}

The template for CAMILLE is a self-contained, computer-mediated learning resource in which the lesson materials take the form of some $40 \mathrm{~h}$ of multimedia exercises and activities that are both highly structured and highly interactive; while the reference materials include a grammar and a notebook for the ury, a book about the target culture, a book about linguistic functions, interaction with the system. With , all of which are accessible at any moment during the user's opportunity to acquire all the skills normally ass of the future tense, the course provides an is aimed at well-motivated adults (the present associated with a threshold level of competence. It adult learners, but the technology could easily be material assumes professionally oriented students), who may or may not be engaged in fo applied to younger learners and advanced access to a tutor (the system was designed tormal education and who may or may not have However, given the curent limis designed to support learners who have no access to a tutor. cannot but enhance the learning expens machine intelligence, regular contact with a live tutor professional as well as leining experience). However, it is assumed that they are motivated by to survive, obtaining food, shelter and Its functional content ranges from the general skills needed skills, using the telephone, making appointments, to what may loosely be described as "business"

This content in turn determined our basic pedagogic approach, which, in general terms, may be described as encouraging the acquisition of a "communicative competence" in a language, by 
(1) 
which we mean acquiring the ability to use language to do things. Thus from the start, the target language is used as the primary language of communication between the computer and the student French). Consequently languagc is available, but access to it is through the target language, world" competencics, but also require he created not only encourage the acquisition of "realimmediate goal of undertaking the exercise. This use the target language in order to mect the instructions in the target language about recording a role in a dialoguc.

However, the adoption of these goal-directed learning strategies does not mean that we have eschewed the teaching of grammar or the exploitation of the computer's ability to engage the development of a flexible linguistic repertore the acquisition of certain linguistic elements. The some "grammar", that permits the use of previous the acquisition of some template for usage, Similarly, certain linguistic skills can of previously acquired knowledge in novel situations. linguistic competence is only achieved by be acquircd with a grcat deal of practice and true To this end we have embedded a by regularly using the language accurately to do something. electronic information support is crucial here. "teach" but to construct an environment short of a live teacher, that they might need to unides students with all the tools and information, practice in conventional "tutor-led" courses[1] undertake a language course. An analysis of existing would normally include some or all of the following: to the view that such tools and information a dictionary, audio- and video-recordings and, very a textbook of learning activities, a grammar, traditional language laboratory. In addition to these frequently, the interactive functionality of a of the language was normally provided by the tutor/or some of all of the cultural cmbedment" was how to make all these varied resources availar some or all of these sources. The problem use manner. The solution lay in the adoption of information and the "electronic desktop" to or the principle of "multi-windowing" to display

When the user enters the CAMILLE environment the screen may be understood to represent a desktop on which a textbook lies open at the table of contents. Surrounding this textbook are button icons representing the reference materials. From this desktop the user may move to any point in the reference sources. Since the objiate item in the table of contents or may choose to open any of the information on demand, they may be these hypertext-reference books is to supply the user with one of the reference sources, it is opened as a separanytime during the course. When the user selects reference books may be open at the same separate window of information on the desktop. All the result is a very cluttered desk. Keeping the textbook in view is impotely covering the textbook, but the the bulk of the user's activity, but also helps to maintain is important, because it not only supports perspace". Furthermore, although the reference materials contain all the in the information "hyacquire the desired level of competence, they offer materials contain all the information needed to

Aurdance on how to acquire it.

This guidance is found in the lesson materials. Although each unit is self-contained, focusing on a particular set of related communication skills, they are not totally independent and cannot Rather they are organized into mix collection of linguistic functions to be studied in any order. grammatical and lexical content of preceding ones. Each new unit and module builds upon the competent learners to begin the course at various points, it is exp, while it is possible for suitably follow the course as designed. Since very few Anglophones are genuine "beginners" inereafter users to assess the a 5 is currently being modified to provide a set of pre-tests, which " French, there is considerable fropriate point of entry to the course for them. Within each will allow undertaken. Moreover, it of choice over the exact order in which particular activitiever, make it possible for a user to move froted that the underlying hypertext particular activities are 
a sludent may, while doing one exercise, look up something in the grammar and from there choose to undertake an exercise designcd to reinforce that point before returning to the original exercise. These activities are normally organized around an "introductory" video sequence which focuses on specific linguistic skills. These skills are further explored and developed in a series of activities and exercises designed to aid in their acquisition. Consequently, the student is strongly encouraged, though not compelled, to watch the video before attempting the exercises. The uscr is not compelled to begin with video because, as will appear later, there are many routes into a unit and, for at least some of these e.g. returning to an uncompleted unit-being compelled to watch the video might be more of an obstacle than an aid.

Within the basic CAMILLE template a unit normally contains some six activities or exercises in addition to the initial video. The video itself is used for aural comprehension tests and quizzes while its transcript is used directly for subtitling and activating the video by sentence and, later more interactively for reading, gapfill/cloze and grammar exercises. Activities/exercises are grouped under the three headings of grammar, function and lexicon depending on their primary focus. The distinction between an activity and exercises or drills is important because it indicates some of the progress that has been made in the field of CALL in recent years. As a general rule, cxercises/ drills tend to be limited repetitive activities designed to provide practice with some very particular skill such as counting or recognizing numbers. An "activity" is less limited in scope and dernands a response from the learncr which is more reflective than reflexive. Thus CAMILLE contains some interactive audio, role-playing exercises which invite the learner to usc numbers within the functional context of acquiring goods or services. It is these more open-ended activitics which are the hallmark

In part because the team adopted a deliberately eclectic approach to the creation of learning activities, it is difficult to list the full range of possibilities that are available to the learner within CAMILLE. Among the more interesting, however, are a larger number of role-playing exercises which exploit both interactive video and interactive audio. In these exercises, the student is invited to adopt the role of one of the interlocutors in a dialogue and participate, by recording their own a pre-recorded example. recorded audio or video utterances. The other interlocutor is also exccuted by means of prepre-recordcd models, but the objective student is prompted and can, if necessary, gain access to of real-life situations. Given the limits of the exercise is to engage the student in the simulation of good faith and co-operation on the part of intelligence, such exercises require a great deal the activity, much seems to be achievable.

In addition to the old favourites like cloze exercises and word squares, there are exercises that permit practice with word-order and lists of keywords and phrases with their English equivalents scrambled so that the students can quiz enhanced to provide pronunciation practice and can be in CAMILLE/France InterActive[2,3] is sound- or Still more significantly, almost every activity only exploits pre-recorded audio or video, it also provides and video-enhanced. The software not playback their own utterances. Because these facilities ares facilities for the student to record and provide an enhanced version of the functionality of traditionailable throughout the course they only provide support for formal exercises but are also avail language. Furthermore, they not student can practice, e.g. pronunciation, on demand.

\section{CAMILLE AS A MULTILINGUAL PLATFORM}

As a consequence of the development of the CAMILLE resource

of the issues immediately facing the Consortium was capable of supporting the development of courseware for languages other than French and
at levels other than beginner. Of course, there was never any question of simply thansling 
InterActive, but if the CAMILLE resource was to be valuable it needed to provide a detailed and viable template and a set of easy-to-use tools that could be applied across a variety of languages.

The Consortium is only 9 months old at the time of writing but, to date, the indications are very encouraging. Perhaps, unsurprisingly, the development of a beginners course in the highly cognate language of Spanish, España InterActiva, appears to offer the fewest problems. Indeed, most of the structures and many of the exerciscs really do seem to be translatable. Nevertheless, there are significant differences between the languages, and these are leading to some important re-thinking of the materials: most obviously, the existence of two verbs "to be", "ser" and "estar," in Spanish and the need to tcach them early in the course means that the Spanish course will have to have a slightly different structure from the French.

More surprisingly, current indications are that the CAMILLE resource will also provide an adequate platform for developing a beginners course in the far less cognate language of Dutch. From the standpoint of CALL, however, one should perhaps not over emphasize the difference between Dutch and the Romance Languages. Like most of them and unlike German, for example, declension does not play a major role in Dutch. Accordingly, it may prove that when the Consortium turns its attention to other Germanic languages more problems will emerge. It would appear that Intcractief Nederlands will also be able to cxploit the model and many of the cxercises in France InterActive. The greatest modifications relate to the grammatical problems of conjugation and word order and more time is spent at the start on orthography and pronunciation. But the functional approach, with a fairly standard grammatical underpinning, seems to be transporting well at this level. While lexicon and grammar are clearly radically different from one language to another, linguistic functions like grectings, writing letters or even more complex activities like seeking a job persist from one linguistic environment to another.

There is another issue related to the transnational utility of a courscware development platform like CAMILLE on which the project hopes to shed some light. Even if the target languages can be approached in a broadly similar fashion, what about the target audience? Will the same course be equally cffective in different countries? There are plans in both Holland and Spain to use France InterActive as it stands to support the acquisition of French by English-speaking Dutch and España InterActivamilarly, the Spanish members of the Consortium are also hoping to make InterActive.

\section{LANGUAGE FOR SPECIFIC PURPOSES}

It does appear that as one moves to another language level or purpose there is a greater need to alter the CAMILLE tcmplate. Accordingly, the use of the platform for developing courses in French Special Purposes (FSP) is generating a range of significant changes. Differences in target template which affect general and principles and this has required alterations to the CAMILLE resources) as well as a more overt shift from cxercises organization (modules, units and general

The FSP modules being developed at Clermont-Ferrand, Travailler en France, is aimed at nonstudied French to at least intermediate level and from a professional emplos of SMEs. They will have or be aware of professional life in their own coun professional viewpoint will have experienced background.

The course combines linguistic and professional goals on the one hand and knowledgc and
know-how on the other[4]. There is a greater emphasis on activities and problem-soving
the basic courses and the focus is on the basic courses and the focus is on communicative strategy and problem-solving than in knowledge. This means that equal weight is given to formal linguistic know-how rather than on 
vocabulary, paralinguistic competence (gesture and bchaviour) and socio-cultural competence (an understanding of the broader context of French professional life). The socio-cultural element cannot be neglected because it has often been observed that a lack of sensitivity to cultural differences between natives and non-natives often leads to a serious degradation of the communication process as well as brcakdown in professional relationships. These competences have to be combined to complete ccrtain defined tasks effectively and efficiently.

The pedagogical approach is based on assumptions common in the teaching of Languages for Specific Purposes[5]. For cxample, considering language learning as a decision-making process, not just as a matter of linguistic knowledge since the learners are already specialists in their own fields, relying on learners first language experience (they are already language users); considering learning as partly incidental (language can be learned when solving a problem not directly related to language as such). Consequently the knowhow aspects of acquisition is more prominent than knowledge/competence. But, the balance between specific professional purposes and more general purposes cannot be ignored. Even though all the linguistic activities are apparently focused on the French business world, thcy remain a subsct of general linguistic competence and performance. For example, basic human interactions such as introductions, farewells and small talk are important in any context. In other words, Language for Specific Purposes is only another way of achieving language acquisition. But the shift in emphasis has required some changes to the basic CAMILLE template.

\section{GENERAL ORGANIZATION}

The emphasis on problem-solving and the greater complexity of the tasks has forced us to abandon the incremental approach of the basic template. Before a specific task can be successfully completed, the learner needs a wide range of specific knowledge and skills related to that task and then needs time to solve problems and complete the practice procedures. Each module contains all the information required by the learner and can be taken in any order. Hence the average time problem-solvinglete a module is between 15 and $20 \mathrm{~h}$, rather than 4 . A further effect of this need to be ming approach and the performance of relatively complex tasks is that the activities the learner more choices and the learner has to take more initiative. Interactive activities give interactive video lacked.

The evaluation of open-ended activities is far more difficult than marking a formal vocabulary or grammatical exercise. Evaluating an activity means identifying the criteria of success and failure linguistic expert knowledge that will, it implies representing explicitly in the computer extralearning a language is more incidental withe machine handle the interaction with the learncr. Since is extremely difficult. Nevertheless, within this perspective, direct evaluation of linguistic ability decision-making abilities, especially in a comer needs some fecd-back on their linguistic and simulation. For instance, if each learner has to plex situation such as a role-playing interactive a personnel manager, they choose a chas to play the role of an applicant in an interview with preceding units. The system then displays all Some criteria belong to the personnel manager (pria by which the dialogue will be evaluated. motivation, etc.), others to the applicant (obtaining (presentation, verbal expression, easc, vitality, salary, etc.). During the interview the video displays only information on the post, negotiating the the manager, each learner selects a written answer from a limite manager. After every utterance by the manager's response. Thecords oneself. This selection is assessed by thens to the corresponding depending on the lease. The dialogue being dynamic, different by the system which determines made up of one's recordingsces. When it ends, the learner can ths and endings are possible evaluate and displays itsings coupled with the video. Then the sysen replay the full dialogue learner can estimays its own evaluation. From the marks generated asks the learner to self 
The foregoing discussion of differences between the France InterActive and Travailler en France frameworks should not obscure the similarities. From a software engineering and a technical viewpoint both projects are strictly similar. Collaborative work has made it possible to enhance some of the concepts introduced in France InterActive and to extend computing and hypermedia facilities to offer the learner a still more active role. In Travailler en France the notebook, linguistic functions, grammar, dictionary books arc very similar to those in France InterActivc. Indecd, thanks to hypertext modularity, it is possible, for instance, to reuse the dictionary directly and just add specific professional vocabulary. FSP may require extra contents and functionalities in some of the books but the principles adopted for the basic template remain unchanged. Next year the portability of Travailler en France will be tested in different countries and when the consortium begins work on an English for Special Purposes course. It is our expectation that exporting the model to other languages will prove no more problematical than exporting France InterActive to Dutch and Spanish.

\section{MANAGING MULTI-NATIONAL MULTIMEDIA PRODUCTION}

As is no doubt obvious from the preceding section, the development of multimedia learning resources requires a wider range of skills and expertise than any individual can realistically be expected to possess. Consequently, the establishment of teams of developers would secm to be a requirement for effective multimedia courseware production. Furthermore, in the field of CALL, it seems likely that such teams will also be multi-national. For examplc, if audio and video materials are to be genuine, they must be produced by native speakers and preferably by native speakers in the target language environment. This can, of coursc, be achieved by taking a film crew and group of native speakers to their country of origin and producing the data. In effect, this is what was done in producing France InterActive. Obviously, however, it is much easier and more efficient to have this production work done by groups of people who are permanently residents in the country of origin and this is what is being done in the CAMILLE project. Teams have been established in France, Holland, Spain and England each of which provides linguistic realism in their own language for the others to use in exploiting the CAMILLE platform to collaborators crage learning resources. However, the establishment of such teams of multi-national communication issues and technical issues.

\section{COMMUNICATION ISSUES}

Most of the following communication issues are obvious, but they are of such importance that they are worth mentioning. For example, although electronic communications of one kind and another do much to speed up contact between partners, they do very little to speed the workings of the bureaucracies, internal and external, which inevitably intervene in the development process. In our experience, where agrcements between partners, e.g. concerning the disposition of funds, or more between the team', e.g. university, bureaucracies a time lag of anything up to 3 months problem, but it does require considerable forward planning and long lead times.

More serious are the related issues of documentation and version maintenance. In the field of CALL relatively few developers are software engineers by profession and, consequently, have not valuable, user-friendly tools for courseware fact that the tools are inadequately documented InterActive were guilty of this. Although the template itself ise degree, the developers of France for its use were less than adequate and this caused some unnecessy easy to use, the instructions implementation of CAMILLE project anyway courseware. These training sessions principally charged with the CAMILLE project anyway and other similar developers would were planned as part of the 
sessions in their planning. Nonetheless, the need for clear accurate documentation of the software is crucial to the efficient running of a transnational development team. Such practice is still more important in the area of version maintenance where it is not only necessary to document changes accurately, but also to communicate those changes to the rest of the team quickly and regularly. Obviously, maintaining fast, effective communications within any team is crucial and the more geographically disparate the members of the team, the more difficult it is to maintain effective contact. However, in this era of electronic communication these problems ought to be minimal. It should be possible to transfer even very complex data relatively quickly and easily by purely electronic means, and one of the project's aims was to see just how far this could be exploited. In our case, two problems were encountered. Initially not all the partners were using the same international network and files were constantly being corrupted as they were switched from one network to another. Secondly, internal networks within universities are not always capable of handling complex multimedia files which can cause frustration and delay.

\section{TECHNICAL ISSUES}

Responding to these communication problems revealed some unexpected tcchnical problems. Since we did not wish to rely entirely on Internet and we needed some kind of local backup system, the acquisition of compatible tape streamers by all the members of the Consortium sccmed a reasonable way forward. It would facilitate both the storage and transmission (by post) of large quantities of data. However, acquiring the same tape streamer in each of the four participating countries proved to be difficult and even when they were acquired different machine configurations from one site to another generated problems. Indeed, this proved to be truc with not only a number of other hardware items, but also with third-party software, where different versions were available in different countries. In the end, problems of machine compatibility proved to be so great that the consortium was forced to the conclusion that in future it might well be necessary not only to articulate hardware/software configurations, but for a single partner to make acquisitions on behalf of all consortium members and to undertake distribution ourselves. The real issue here is that, as yet, it seems likely that, the MPC standard notwithstanding, the trans-national distribution of multimedia courseware may not prove as trouble-free as one might have supposed. One example of this calls atttention to another technical issue that deserves some consideration. In an effort to exploit the MPC standard, CAMILLE decided to move to. WAV files for the storage and retrieval of audio data and we all bought what we thought were the same 16 bit sound cards. In the event, it turned out that half of us had cards which would record at 16 bits per channel while the others could only record and play back at 8 bits per channel. We have yet to decide which standard to go for. At the present moment, 8 bit cards far outnumber the higher quality 16 bit cards, but for

Of course, working in the field of multimedia one must expect the technology to move on and one cannot always expect backwards compatibility. At least one cannot, if quality is a serious by the quest for only has to consider the limitations imposed on the whole DOS environment assessment of what the delivery technolity. However, this does remind one to make a serious aims at today's technology it will go likely to be when the courseware is finished. If one but if one constantly chases the state of date during the development life-cycle of the courseware unending revision cycle or producing software that requires of either becoming involved in an delivery platform. What is necded is software that requires a prohibitively novel or cxpensive most likely to be dominating the market at the end some reasonable assessment of the technology

Perhaps even more importantly, this quandary argues a very strong case for producing and is one of the all audio and video data in a machine-independent format. Audio-video production to short-circuit this time consuming and expensive parts of multimedia authoring; and it is tempting files directly in the computer environmentern technology lo produce digital sound and video 
production is likely to tie the devcloper to a specific hardware/software delivery platform and this platform may, as the SoundBlaster 16 story indicates, rapidly become out-dated. It is better to produce and store all sound and video on traditional tape media. In this way, if the technology moves on, it is possible to move with it. There will be some necessary re-programming, but that activity is trivial in comparison with the task of reproducing the original audio or video matcrials.

\section{CONCLUSIONS}

It will be clear that the project has so far given us cause for optimism on the question of portability and the use of standardized templates. But the proof of the pudding is in the eating and the fundamental issues relating to the use of modern technology in language teaching have not yet been widely addressed. We will not be able to take a position to view for another year.

From a pedagogical viewpoint, hypermedia technologies are often presented as an opportunity to enhance language learning: they endow the previously restricted computing environment with extra channels of communication; they increase possibilities of interaction and they give the learner more control. Although these factors are often assumed to play an important role in the acquisition process, there is as yet little evidence either to support or to refute the assumption. The CAMILLE project offers an opportunity to undertake such an examination in a multi-cultural environment.

From a software engineering viewpoint, hypermedia programming tools are often advocated as an opportunity to speed up courseware development, and hence to make CAL a realistic support for trainers and teachers. But hypermedia production requires a wide range of skills and up to now our experience in re-using software modules for large scale software is still
very limited[6].

Acknowledgement - The CAMILLE project is funded by the European LINGUA programme.

\section{REFERENCES}

1. Ingraham B. D. and Emery C. R., France InterActive: a hypermedia approach to CALL. ETTI 28, $321-333$ (1991). Gimeno-Sanz A,). Universidad Politécnica de Valencia (1993).
Ingraham B. D. and Emery C. R.

Officc for Humanities Publication No, 2, Oxford University Computing Centre CALL. In Computers and Language. 93-101 (1992)

5. Hutchinson T. and Waters A. English for Francais Professionnels. LINX 27, pp. Cambridge (1987). 6. Ingraham B. D., Nut a cottage industry. Proceedings of and Future Applications. University of Southhampton. In press. 